\title{
HEALTH PERCEPTION AND FOOD CHOICE FACTORS IN PREDICTING HEALTHY CONSUMPTION AMONG ELDERLY
}

\author{
Dagmar Lesakova ${ }^{1}$ \\ ${ }^{1}$ Department of Marketing, Faculty of Commerce, University of Economics in Bratislava, Dolnozemska 1, 85235 \\ Bratislava, Slovak Republic
}

To cite this article: LESAKOVA DAGMAR. 2018. Health Perception and Food Choice Factors in Predicting Healthy Consumption Among Elderly. Acta Universitatis Agriculturae et Silviculturae Mendelianae Brunensis, 66(6): 1527-1534.

To link to this article: https://doi.org/10.11118/actaun201866061527

\begin{abstract}
The main objective of the paper is to explore the impact of health perception and food choice factors on healthy food consumption among elderly and to indicate how different food choice motives influence the eating behaviour of elderly population. In our research we explore six food choice factors and their manifestation in attitudes towards healthy consumption. The purpose of the exploration of health perception is to identify seniors beliefs about food and health-related aspects. Empirical research was conducted on a random sample of 400 elderly participants aged above 65 years and living in their own flats. Non-probability sampling in the form of convenience sampling was employed. The relationship between health beliefs and attitudes towards healthy eating behaviour was confirmed with employing multiple regression analysis. We conclude that both health beliefs and food choice factors investigated in the research are important determinants of seniors' healthy consumption, however with different effect on healthy eating behaviour.
\end{abstract}

Keywords: health beliefs, food choice motives, healthy eating behaviour, seniors

\section{INTRODUCTION}

Older people represent an increasing proportion of the population. Health or its absence in this rapidly increasing population not only affects the seniors themselves, but also has serious implications on health care and other social resources. There has recently been a move away from considering old age to be a problem in itself and the focus has shifted towards older people's possibilities to improve quality of their life (Luca and Suggs, 2013; Moschis et al., 2011). Successful ageing is described as decreasing the risk of diseases while maintaining physical and mental functioning and active engagement in societal participation. The World Health Organization's (2002) active ageing policy framework identified the key concepts of productive ageing (i.e. The ability to contribute directly and indirectly in older age) and healthy ageing (i.e. The ability to remain physically and mentally fit). The recognition to focus on personal health goals and individual perceptions of the "well-being" calls also for the research in the area of food and nutrition in relation to older people's quality of life (Stremersch, 2008).

Nutrition is recognized as one of the major determinants of successful ageing, defined as the ability to maintain three key qualities: low risk of disease and disease related disability, high mental and physical function, and active engagement in life (Kraft and Goodell, 1993). Good and proper nutrition can significantly reduce the likelihood of developing a number of common chronic diseases and slow down their progression (Drolet et al., 2010). 
It is thus important to understand what influence older people's food-related behaviour.

The meaning of health in the process of ageing has been investigated in a number of studies (Divine and Lepisto, 2005; Luomala et al., 2015) supporting the concept of health as a multidimensional construct, comprising a state of complete physical, mental and social well-being and not merely the absence of disease. We adopt this multidimensional perspective on health by considering the impact of several economic, psychological and social health motive dimensions.

As people age their living circumstances may alter. For example, as people retire, their income falls down and their social network may reduce. As health changes for worse, access to shops may become a problem (Darian and Tucci, 2011). Further, loss of the partner due to death of spouse or children leaving home, may change cooking and eating circumstances (Kraft and Goodell, 1993). All these factors with becoming older affect older people's behaviour towards food and their satisfaction with food-related life (Kritchevsky, 2016).

By identifying older people's health-related beliefs, their food-choice motives and the relevance of these motives in achieving health goals we can investigate the relationships between health-related beliefs, motives and healthy food consumption. A scientific unity exists for a strong association between diet and risk of various diseases, particularly cardiovascular disease, obesity and certain types of cancer. Hence, need to adopt healthier diets are important in seniors' eating behaviour (Keane and Willetts, 1994; Dean et al., 2008). Several previous studies explored the relationship between demographic characteristics and health consciousness, food choice motives, attitudes towards healthy eating and eating behaviour (Sparks et al., 2001; Bower et al., 2003), however, the investigation of the interrelationships among these variables was rather neglected. Furthermore, previous research about healthy eating behaviour was mostly descriptive, with little attention to the explanation of health-related beliefs and food choice motives.

The objectives of our research are threefold. First, the existence of two subgroups will be explored within elderly population for whom health goals and health beliefs have different distinct meaning (personal well-being vs preventing diseases). Second, these two resulting segments will be compared with respect to several food choice motives. The third objective lies in the analysis of the role which the food choice motives play in the intersection between health beliefs and healthy eating behaviour.

\section{MATERIALS AND METHODS}

The sample consisted of 400 seniors, aged $65+$. Seniors were interviewed in 12 randomly chosen daily senior centres in five towns of Western and Middle Slovakia. Gathering the sample from daily senior centres provided us with the additional advantage that the senior citizens will be both living in their own flats and be mobile, and thus they could be in the position to choose to buy their foods individually. We included in the total sample at each of the chosen centres those individuals who agreed to participate in the survey. Empirical research was carried out between October 2017 and December 2017. The majority of the respondents were female (58\%), which is similar to the female proportion in this age-population (60\%), hence providing some confidence for the representativeness of the sample to the studied population. About sixty-six percent of the respondents were aged between 65 and 75 years, while the remaining thirty-four percent were older than 75 years.

The questionnaire consisted of questions exploring three areas: health beliefs, food choice motives and healthy eating behaviour. For the purpose of analysing the health beliefs, we used a modified scheme proposed by Kähkonen et al. (1996) and used 10 items linked to health. The purpose of the health beliefs scale was to reveal seniors' beliefs about

I: Demographic profile of respondents

\begin{tabular}{lcc}
\hline \multicolumn{1}{c}{ Variable } & Frequency & Valid percentage \\
\hline Sex & 171 & \\
Male & 229 & 42.7 \\
Female & & 57.3 \\
Age group & 109 & 27.3 \\
$\mathbf{6 5 - 7 0}$ & 158 & 39.5 \\
$\mathbf{7 1 - 7 5}$ & 107 & 26.8 \\
$\mathbf{7 6 - 8 0}$ & 26 & 6.5 \\
$\mathbf{8 1 +}$ & & \\
Location size (population) & 168 & 42.0 \\
$\mathbf{>}$ 100 Thousand & 140 & 35.0 \\
$\mathbf{5 0 - 1 0 0}$ Thousand & 92 & 23.0 \\
$\mathbf{2 5 - 5 0}$ Thousand & & \\
\hline
\end{tabular}


health and food related aspects (Iely et al., 2001). Subjects were asked: "When thinking about health, how important are following aspects for you?" The degree of importance was rated on a 5-point Likert scale ( $1=$ very unimportant; $5=$ very important). The score of individual health belief items is presented in Tab. II.
In order to simplify the initial items, factor analysis was conducted on the belief items. Two factors were extracted and the total variance explained by this solution was $69,16 \%$. Factor loading of greater than 0.40 was the criterion for accepting a statement into a factor. The results of this factor analysis determined two types of health beliefs, which were: personal

II: Health beliefitems (HBI) scale

\begin{tabular}{lccc}
\hline & Belief items & Loading & Cronbach's $\boldsymbol{\alpha}$ \\
\hline HBI1 & Personal well-being & & 0.85 \\
HBI2 & Content of cholesterol in foods & 0.764 & \\
HBI3 & Content of fat in foods & 0.802 & \\
HBI4 & Content of salt in foods & 0.821 & \\
HBI5 & Content of sugar in foods & 0.865 & 0.801 \\
HBI6 & Nutrition information & 0.793 & \\
HBI7 & Gaining weight & 0.782 & \\
HBI8 & Preventing diseases & 0.766 & \\
HBI9 & Physical activities, walking, exercise & 0.793 & \\
HBI10 & Active participation in community life & 0.810 & \\
\hline
\end{tabular}

Source: own calculation

III: Food choice motives by elderly

\begin{tabular}{|c|c|c|}
\hline It is important for me that the food I consume: & Loading & Cronbach's $\alpha$ \\
\hline Factor 1 - Health & & 0.872 \\
\hline Is nutritious & 0.801 & \\
\hline Is healthy & 0.749 & \\
\hline Contains lots of vitamins and minerals & 0.622 & \\
\hline Contains natural ingredients & 0.602 & \\
\hline Contains no artificial ingredients & 0.511 & \\
\hline Factor 2 - Price & & 0.901 \\
\hline Is cheap & 0.828 & \\
\hline Is not expensive & 0.816 & \\
\hline Is good value for money & 0.788 & \\
\hline Factor 3 - Mood & & 0.839 \\
\hline Helps me feel good & 0.740 & \\
\hline Keeps me awake/alert & 0.686 & \\
\hline Helps me to cope with life & 0.653 & \\
\hline Factor 4 - Familiarity & & 0.790 \\
\hline Is what I usually eat & 0.722 & \\
\hline Is familiar to me & 0.704 & \\
\hline Is like the food I consumed when I was younger & 0.670 & \\
\hline Factor 5 - Sensory appeal & & 0.801 \\
\hline Has a pleasant taste & 0.766 & \\
\hline Has a pleasant smell & 0.695 & \\
\hline Has a pleasant appearance & 0.655 & \\
\hline Factor 6 - Weight control & & 0.745 \\
\hline Is low in fat & 0.682 & \\
\hline Is low in calories & 0.654 & \\
\hline
\end{tabular}

Source: own calculation 
well-being (HBI7-HBI10) and preventing diseases (HBI1-HBI6) with alpha coefficients of 0.85 and 0.81 respectively.

Food choice motives were measured by 19 items, adapted from Kraft and Goodell (1993), and Jayanti and Burns (1998). Respondents were asked to express the importance of their motives in the choice of foods on a 5-point Likert scale, where $1=$ very unimportant and $5=$ very important (Tab. III). Six factors resulted from the 19-item food choice motives and they were: health, price, mood, familiarity, sensory appeal and weight control. The calculated alpha coefficients for the food choice motive factors ranged from 0,745 to 0,901 .

To measure the attitudes towards healthy eating behaviour, we applied a modified 3-item scale from Kearney et al. (2001). The items were: "I make conscious effort to eat a healthy diet"; "I eat to a healthy amount"; and "I don't need to make changes to my diet as it is healthy enough" (Tab. IV). Respondents were asked to select the most appropriate response using a 5-point Likert scale ranging from "most of the time" to "hardly ever" for the first two statements and ranging from "strongly agree" to "strongly disagree" for the third statement (Ajzen and Fishbein, 1989).

The research confirmed uni-dimensionality for attitudes towards healthy eating behaviour, with Cronbach's alpha 0,796.

Internal consistency of the scales regarding the measures of health beliefs, food choice motives and of healthy eating behaviour was assessed on Cronbach's alphas and inter-correlations. Factor analyses served as the basis for validity examinations. Three separate principal component analyses were performed: one for health beliefs, one for food-choice motives and one for eating behaviour. To analyse the effect of the food choice motives as the mediating variables between health beliefs and healthy eating behaviour, mediation analysis requires the regression of the dependent variable on the independent variable, the regression of the mediator on the independent variable, and finally regression of the dependent variable on both the independent variable and mediating variable. In this context hierarchical regression analyses included: first, regression of food-choice motives (dependent variable) on health beliefs (independent variable); second, regression of healthy eating behaviour (dependent variable) on health beliefs (independent variable); and finally, regression of healthy eating behaviour (dependent variable) on both the health beliefs and food choice motives (independent variables). At this final regression step, only the effects of the mediators (food choice motives) should be significant for full mediating effect.

\section{RESULTS AND DISCUSSION}

As mentioned in previous paragraphs, a PCFA (Principal Component Factor Analysis) was applied to the 19 items of the food choice motives in order to group the motives. As a result of this process, six factors were obtained (Tab. III), which together explain $63.49 \%$ of the variance.

The first factor "Health" contains 5 items that are associated with health and the natural content of the foods. This combination is due to the fact that people usually consider "natural ingredients" with something healthy. The second factor "Price" includes 3 items linked to the economic value of the food. The third factor "Mood" is related to physical and emotional well-being resulting from foods consumption. Items of "Familiarity" factor reflect their distinct relevance and applicability to older consumers. The fifth factor "Sensory appeal" comprised three items related to the principal senses related to taste and smell. Finally, the last sixth factor "Weight control" refers to two items and it did not seem to be as important aspect as it may be in younger consumers' population. The reason can be that even if the seniors eat everything, they eat it in moderation, in smaller portions.

In order to indicate the importance that each factor has in the choice of food, the average score for each of the six identified factors was calculated (mean and standard deviation). As shown in Tab. V, the most important factor for elderly people in choosing their food is Price (achieving the score of 4.33), followed by health (4.19) and mood (3.92). The least valued factor was Weight control, which scores 2.95 (out of 5), suggesting that elderly (in contrast to younger people) do not seem to be very concerned about putting on weight, even though their knowledge about foods nutritional content is relatively high. This is an interesting result, which was found similar in research of Brown et al. (2000), confirming that consumers' high levels of nutrition awareness may not be reflected in their food behaviour. The mean value of factor Mood (3.92) indicates that the mood plays an important role in eating behaviour of elderly. The Sensory appeal is valued (3.80) slightly below the average value of Mood, suggesting that seniors may identify good mood with tasty food. The Familiarity associated with the previous knowledge of the food seems to be

\begin{tabular}{ll}
\hline \multicolumn{1}{c}{ I agree with the following statement: } & Loading \\
\hline Factor 1: Healthy eating behaviour & Cronbach's $\alpha$ \\
\hline I make conscious effort to eat a healthy diet & 0,812 \\
I eat to a healthy amount & 0,704 \\
I don 't need to make changes to my diet as it is healthy enough & 0,493 \\
\hline
\end{tabular}


important in the choice of a food, perhaps because seniors do not like to try new products and to taste new foods. Factor Health obtained very similar results (4.19) to the results of factor Price, which shows that seniors are aware of the importance of taking care of their health with adequate nutrition, however they are also concerned and limited with their financial possibilities.

Two concepts were identified to be important for senior consumers, i.e. health is about personal well-being (life is enjoyable) and health is about preventing diseases (energy and autonomy). This outcome is also in line with previous research by other authors (Kähkönen et al., 1997; Moorman and Matulich, 1993; Papies et al., 2007). It was found that respondents had stronger health belief for personal well-being than they had for preventing of diseases. Although the two health belief factors affected the food choice motive of health, as it was expected, they both also effected the food choice motive of familiarity. This suggests that seniors with more health beliefs not only place more importance on choosing food that make them physically healthier, but also prefer familiar food and habits from the past.

Tab. V shows the correlations among health beliefs variables, food choice motives factors, and attitudes toward healthy eating behaviour. As expected, health belief of personal well-being had the greatest effect on the mood motive followed by the health motive, familiarity and sensory appeal; while health belief of preventing diseases had the greatest effect on food choice motives of health, weight control, price and familiarity. Although the two health beliefs factors affected the food choice motive of health, as expected, they both also affected the food choice motive of familiarity. The findings suggest that individuals with higher health beliefs not only place more importance on choosing food that make them healthier, but also prefer familiar food.

The analysis of interrelationships among variables was performed using seven hierarchical regression equations. In the first six equations, the health beliefs factors were considered as the independent variable and regressed on the six food choice motives. These six equations test the relationships between health beliefs factors and six food choice motive factors. In the seventh equation, all eight of these factors (two health beliefs factors plus six food choice motives) were treated as independent variables and regressed on healthy eating behaviour. This last equation tests the link between the beliefs and food choice motives as independent variables to healthy eating behaviour. Tab. VI summarizes the results of these seven hierarchical regression equations.

It was found that health beliefs did not affect all food choice motives and not all food choice motives were statistically associated with healthy eating behaviour.

In each of the first six equations, health belief of preventing diseases was statistically significant with all food choice motive factors, except of sensory appeal and mood. However, only three food choice factors were statistically associated with healthy eating behaviour, namely, the health motive, the price motive, and the mood motive. Hence, we can conclude that seniors exhibiting belief of preventing diseases would place higher importance on health and price in food-related decisions and attitudes toward healthy eating.

On the other hand, seniors exhibiting higher belief for personal well-being put more emphasis on health, mood, sensory appeal and familiarity in their food-related decisions. However, among these food choice motives, only health and mood were significantly associated with healthy eating behaviour. It means, that seniors' belief for personal well-being would both directly influence their healthy eating behaviour and indirectly influence this behaviour via the food choice motives of health and mood. Among all six food choice motives factors the best predictability from health belief factors had the motive health followed by mood and familiarity. Sensory appeal and price had the least predictability from health concern factors. The seventh equation, regressing healthy eating behaviour as a function of two health beliefs factors and six food choice motives contained no multicollinearity.

V: Means, standard deviations and inter-correlations of research variables

\begin{tabular}{|c|c|c|c|c|c|c|c|c|c|c|c|}
\hline & $\mathbf{M}$ & SD & 1 & 2 & 3 & 4 & 5 & 6 & 7 & 8 & 9 \\
\hline 1 Personal well-being & 4.12 & 0.71 & $(0.85)$ & & & & & & & & \\
\hline 2 Preventing diseases & 4.02 & 0.64 & $0.68 * *$ & $(0.81)$ & & & & & & & \\
\hline 3 Health & 4.19 & 0.61 & $0.63 * *$ & $0.58 * *$ & $(0.87)$ & & & & & & \\
\hline 4 Sensory appeals & 3.80 & 0.84 & $0.36^{* *}$ & $0.28 * *$ & $0.29 * *$ & $(0.80)$ & & & & & \\
\hline 5 Mood & 3.92 & 0.81 & $0.56^{* *}$ & $0.44 * *$ & $0.58^{* *}$ & $0.42 * *$ & $(0.83)$ & & & & \\
\hline 6 Weight control & 2.95 & 0.86 & $0.16^{* *}$ & $0.32 * *$ & $0.41^{* *}$ & $0.15^{* *}$ & $0.31^{* *}$ & $(0.74)$ & & & \\
\hline 7 Price & 4.33 & 0.45 & $0.38^{* *}$ & $0.30^{* *}$ & $0.23 * *$ & $0.21^{* *}$ & $0.26^{* *}$ & $0.19 * *$ & $(0.90)$ & & \\
\hline 8 Familia-rity & 3.75 & 0.99 & $0.29 * *$ & $0.34 * *$ & $0.29 * *$ & $0.32^{* *}$ & $0.30^{* *}$ & $0.33 * *$ & $0.38^{* *}$ & $(0.79)$ & \\
\hline 9 Healthy eating attitudes & 3.91 & 0.89 & $0.47 * *$ & $0.45^{* *}$ & $0.58^{* *}$ & $0.32 * *$ & $0.39 * *$ & $0.27^{* *}$ & $0.40^{* *}$ & $0.32 * *$ & $(0.84)$ \\
\hline
\end{tabular}

Source: own calculation

Note: The numbers on the diagonal are the coefficients alphas. $\mathrm{M}=$ mean value of variables. 
VI: Regression analysis results (mediating effect of food-choice motives on attitudes towards healthy eating)

\begin{tabular}{|c|c|c|c|c|c|c|c|c|}
\hline & \multirow[b]{2}{*}{ Health } & \multirow[b]{2}{*}{$\begin{array}{l}\text { Sensory } \\
\text { appeal }\end{array}$} & \multirow[b]{2}{*}{ Mood } & \multirow[b]{2}{*}{$\begin{array}{l}\text { Weight } \\
\text { control }\end{array}$} & \multirow[b]{2}{*}{ Price } & \multirow[b]{2}{*}{ Familiarity } & \multicolumn{2}{|c|}{ Eating attitudes } \\
\hline & & & & & & & FB & $\begin{array}{c}\text { FB+ } \\
\text { FM } \\
\end{array}$ \\
\hline \multicolumn{9}{|l|}{ I. Health beliefs } \\
\hline Personal well-being & $0.24 * * *$ & $0.13 *$ & $0.42 * * *$ & 0.29 & 0.36 & $0.23 * * *$ & $0.40^{* * *}$ & $0.29 * * *$ \\
\hline Preventing diseases & $0.36^{* * *}$ & 0.20 & 0.40 & $0.18^{* *}$ & $0.40^{*}$ & $0.18 *$ & $0.32 * * *$ & 0.18 \\
\hline \multicolumn{9}{|c|}{ II. Food choice motives } \\
\hline Health & & & & & & & & $0.47^{* * *}$ \\
\hline Sensory appeal & & & & & & & & 0.09 \\
\hline Mood & & & & & & & & $0.14 *$ \\
\hline Weight control & & & & & & & & -0.06 \\
\hline Price & & & & & & & & $0.23 * *$ \\
\hline Familiarity & & & & & & & & 0.03 \\
\hline R2 & 0.45 & 0.09 & 0.21 & 0.19 & 0.15 & 0.10 & 0.28 & 0.41 \\
\hline
\end{tabular}

Note: $\mathrm{FB}=$ Food beliefs; FM = Food choice motives; ${ }^{*} \mathrm{p}<0.05,{ }^{* *} \mathrm{p}<0.01,{ }^{* * *} \mathrm{p}<0.001$

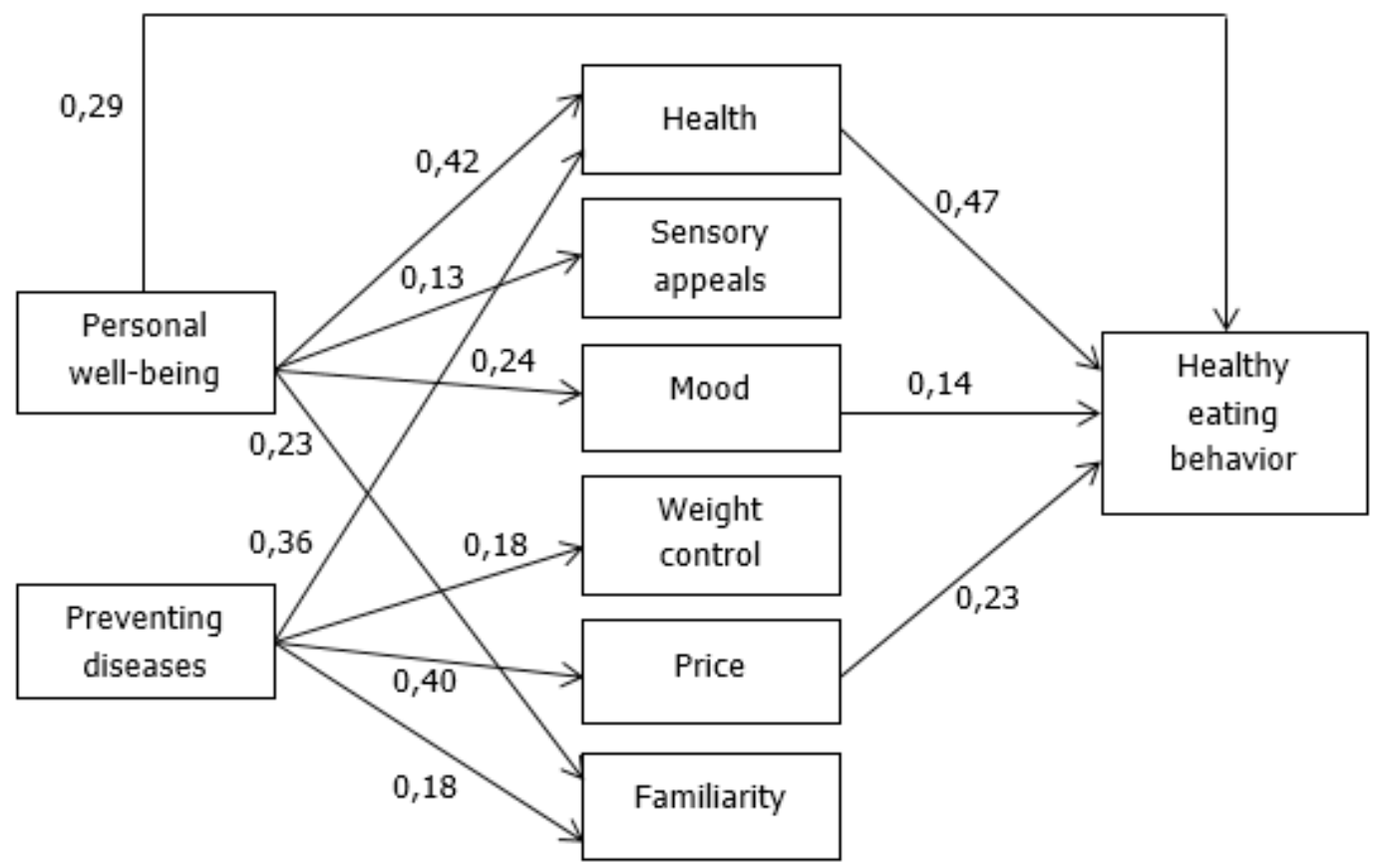

1: Diagram of interrelations among health beliefs, food choice motives and healthy food behaviour Source: own elaboration

Both health beliefs of personal well-being and preventing diseases were statistically associated with healthy behaviour and accounted for $28 \%$ of the variance in attitudes toward healthy eating. Adding our six food choice motive factors to two health concern factors in predicting healthy eating behaviour resulted in a a total of $41 \%$ of the variance in attitudes toward healthy eating behaviour. At this final stage, only health belief of personal well-being and food choice motives of health, mood, and price could significantly predict attitudes toward healthy eating behaviour. It indicates a full mediation of food choice motives between health belief of personal well-being and healthy eating behaviour and partial mediation of food choice motives between health belief of preventing diseases and healthy eating behaviour. A final diagram of the interrelations is shown in Fig. 1.

Our final results show that health belief of personal well-being had a greater effect on eating behaviour than did health belief of preventing diseases. The reason could be that seniors attach to the food only a secondary role among the reasons of their diseases. Hence, seniors who represent health belief of personal well-being, exhibit eating behaviour that is more cautious than it is by seniors exhibiting belief of preventing diseases. 


\section{CONCLUSION}

The principal objective of our research was to explore the effect of health beliefs on healthy eating behaviour. In particular, the question was raised, whether this effect on healthy eating behaviour could be mediated by food choice motives. Hence, the examination was focused on the affection of beliefs and motives towards eating behaviour with food choice motives playing a mediating role.

It was documented that health beliefs did not affect all food choice motives and not all food choice motives were statistically associated with healthy eating behaviour. We found that seniors with different health beliefs exhibit different food choice motives. Seniors exhibiting health belief of "preventing diseases" putmore importance on food-choice motives health, mood, price and familiarity of the food. However, only 3 food-choice motives are statistically associated with healthy eating behaviour (health, price and mood). Based on this result it can be concluded that seniors with health belief of "preventing diseases" would place higher importance on health and price in their healthy eating behaviour. On the other hand, seniors representing health belief of "personal well-being" put more emphasis on food choice motives of health, mood, sensory appeal and familiarity. Among these motives only health and mood are significantly associated with healthy eating behaviour. The results of hierarchical multiple regression analysis document that health belief of personal well-being would both a) directly influence their healthy eating behaviour, and b) indirectly influence this behaviour through two of the food-choice motives, which are health and mood. The research results indicate the mediating impact of food-choice motives on healthy eating behaviour.

Against our expectations health belief of personal well-being and mood motive are better predictors than weight control in the creation of healthy eating behaviour. Among all the variables, the food choice motive health exhibited the strongest direct influence on healthy eating behaviour, followed by health belief of personal well-being and food choice motives of mood and price.

The interrelations between beliefs, motives and behaviour offer an interesting area for future research. Especially, the variables mediating or moderating the effect of health beliefs on healthy eating behaviour open areas for future research. Our results indicate for example that health belief affects the food choice motives of familiarity, however, this motive does not affect healthy eating behaviour in our study. Future research can further explore the possible effects of this motive and its manifestation in healthy eating behaviour. In addition, researchers should concentrate more to identifying the variables that mediate or moderate the effect of health belief on healthy eating behaviour.

Determining the attitudes of senior population towards their diet and to particular food may be useful in nutrition educational campaigns for identifying target groups for whom specific nutrition messages would be appropriate. Therefore, subjects promoting healthy eating could emphasize the importance of health and healthy environment in creating food-related decisions. The emphasis on mood and familiarity motive in promotional campaigns can also help in development of positive approach to healthy eating behaviour. The findings of this research could be used in improving seniors-oriented food offerings, product positioning and marketing communication towards seniors in the category of foods.

Potential limitation of the study is the range of seniors included in the research, as well as the specific senior's centres context in which the study was conducted. Further research needs to include a broader sampling method, stretching across different geographic regions, with both urban and rural population, as well as various inputs with respect to educational level and living conditions. Furthermore, the research did not consider health status when investigating the relationships among health beliefs, food choice motives and healthy eating behaviour. Future research might seek to determine the effects of various manifestations of health beliefs. For example, besides belief of preventing diseases and personal well-being, perhaps other types of health beliefs can also predict attitudes toward healthy eating.

\section{Acknowledgement}

This research was conducted as a part of the research project VEGA 1/0339/18 "Health conscious consumer behaviour: determinants, perspectives and intervention possibilities".

\section{REFERENCES}

AJZEN, I. and FISHBEIN, M. 1989. Understanding attitudes and predicting social behaviour. New York: Prentice Hall. BOWER, J. A., SAADAT, M. A. and WHITTEN, C. 2003. Effect of liking, information and consumer characteristics on purchase intention and willingness to pay more for a fat spread with a proven health benefit. Food Quality and Preference, 14(1): 65-74.

BROWN, K., MCILVEEN, H. and STRUGNELL, C. 2000. Nutritional awareness and food preferences of young consumers. Nutrition $\odot$ Food Science, 30(5): 230-235. 
DARIAN, J. C. and TUCCI, L. 2011. Perceived health benefits and food purchasing decisions. Journal of Consumer Marketing, 28(6): 421-428.

DEAN, M. S., GRUNERT, K. G., RAATS, M. M., NIELSEN, N. A. and LUMBERS, M. 2008. The impact of personal resources and their goal relevance on satisfaction with food related life among the elderly. Appetite, 50(4): 308-315.

DIVINE, R. L. and LEPISTO, L. 2005. Analysis of the healthy lifestyle consumer. Journal of Consumer Marketing, $22(5): 275-283$.

DROLET, A. L., SCHWARZ, N. and YOON, C. 2010. The Aging Consumer: Perspectives from Psychology and Economics. New York, N.Y: Routledge.

IELY, M., FLYNN, A., HARRINGTON, K. E., ROBSON, P. J. and CRAN, G. 2001. Sampling description and procedures used to conduct North/South Ireland Food Consumption Survey. Public Health Nutrition, 4(5A): 1029-1035.

JAYANTI, R. K. and BURNS, A. C. 1998. The Antecedents of preventive health care behavior. An empirical study. Academy of Marketing Science, 26(1): 9-15.

KÄHKÖNEN, P., TUORILA, H. and LAWLESS, H. 1997. Lack of effect of taste and nutrition claims on sensory and hedonic responses to a fat-free yogurt. Food Quality and Preference, 8(2): 125-130.

KÄHKÖNEN, P., TUORILA, H. and RITA, H. 1996. How information enhances acceptability of a low-fat spread. Food Quality and Preference, 7(2): 87-94.

KEANE, A. and WILLETTS, A. 1994. Factors that affect food choice. Nutrition $\sigma$ Food Science, 4(1): $15-17$.

KEARNEY, J. M., GIBNEY, M.J., KIVINGSTONE, M. B., ROBSON, P. J., KIELY, M. and HARRINGTON, K .E. 2001. Attitudes towards and beliefs about nutrition and health among a random sample of adults in the Republic of Ireland and Northern Ireland. Public Health Nutrition, 4 (5): 1117-1126.

KRAFT, F. B. and GOODELL, P. W. 1993. Identifying the health conscious consumer. Journal of Health Care Marketing, 13 (3): 18-25.

KRITCHEVSKY, S. B. 2016. Nutrition and Healthy Aging. Journal of Gerontology: Medical Sciences, 71(10): 1303-1305.

LUCA, N. R. and SUGGS, L. S. 2013. Theory and model use in social marketing health interventions. Journal of Health Communication, 18(1): 20-40.

LUOMALA, H., JOKITALO, M., KARHU, H., HIETARANTA-LUOMA, H. L., HOPIA, A. and HIETAMÄKI, S. 2015. Perceived health and taste ambivalence in food consumption. Journal of Consumer Marketing, 32(4): 290-301.

MOORMAN, C. and MATULICH, E. 1993. A Model of Consumers' Preventive Health Behaviors: The Role of Health Motivation and Health Ability. Journal of Consumer Research, 20(2): 208-228.

MOSCHIS, G. P., MOSTELLER, J. and FATT, C. K. 2011. Research Frontiers on Older Consumers' Vulnerability. The Journal of Consumer Affairs, 45(3): 467-491.

PAPIES, E., STROEBE, W. and AARTS, H. 2007. Pleasure in the mind: restrained eating and spontaneous hedonic thoughts about food. Journal of Experimental Social Psychology, 43(5): 810-817.

SPARKS, P., CONNER, M., JAMES, R., SHEPHERD, R. and POVEY, R. 2001. Ambivalence about health - related behaviors: An exploration in the domain of food choice. British Journal of Health Psychology, 6(1): 53-68.

STREMERSCH, S. 2008. Health and marketing: The emergence of a new field of research. International Journal of Research in Marketing, 25(2): 229-233. 